（85） 非ニュートン流停止後の応力緩和

第 1 報 形式論的考察

(1966年 2 月24日受理)

黒岩城雄*. 中村亦夫*

要 旨 応力緩和に対する Maxwell の一般式は,

$$
\frac{d \sigma}{d t}=-\frac{\sigma}{\tau}
$$

である。 $\sigma$ の単調減少関数であるては (2) 式のように書けるものとする。 $\tau=\tau^{0}\left(1+a \sigma+b \sigma^{2}+c \sigma^{3}+\cdots \cdots\right)$

ここで， $a, b, c, \cdots \cdots$ は物質定数， $0 \geqq a \sigma+b \sigma^{2}+c \sigma^{3}+\cdots \cdots \geqq-1$ で， $:^{0}$ は微小応力下，示の緩和時 間である。(1)，(2) 式より，緩和の終端領域に対し，(3) 式が導かれる。

$$
\frac{\sigma^{*}}{\sigma_{0}} \fallingdotseq B e^{-t / 0^{0}}
$$

ここで， $\sigma_{0}$ は $t=0$ のときの $\sigma, \sigma^{*}$ は一般線形粘弾性論が適用できる範囲の小さい灾力を意味す る。 $B$ は $\sigma_{0}$ の関数であり, $t$ には無関係である。

もし， $\sigma_{0}=\eta \dot{r}(\dot{\gamma}:$ ズリ速度， $\eta$ : 非ニュートン粘性）ならば，（3）式は

$$
\frac{\sigma^{*}}{\dot{\gamma}} \fallingdotseq \eta B e^{-t / \tau 0}=\eta^{*} e^{-t / \tau 0}
$$

で表わされる。ク*は“流動停止後の応緩和における非ニュートン係数”とでも呼忍゙ききのであ る。

ての非線形項の関数形,すなわち, $\left(a \sigma+b \sigma^{2}+c \sigma^{3}+\cdots \cdots\right)$ は (5) 式から定めることができよう。

$$
\frac{d \log B}{d \log \sigma_{0}}=a \sigma_{0}+b \sigma_{0}^{2}+c \sigma_{0}^{3}+\cdots \cdots
$$

上述の巨視的形式論を Eyring-Tobolsky の理諭と比較し，また，種々の非線形粘弹性溶液によっ て検討した。

ここに提案した理論の応用については第 2 報で述べようと思う。

\section{1. 緒言}

既報1)でカルボキシメチルセルロース (CMC) 溶液の 非ニュートン流停止後の応力髣和を観測した際, $\log (\sigma /$ $\dot{\gamma}) \sim t(\sigma$ : 緩和におけるズリ応力, $\dot{\gamma}:$ 定常流におけるズ リ速度, $t:$ 時間)の形でプロットした応力緩和曲線の終 端領域は，ほぼ平行な直線となることを認めた。

本報は，このような現象の一般性を検討し，非ニュー トン液体の最長緩和機構，すなわち，分子間の相互作用 を明らかにする目的で行なった実験結果に関するもので あるが，実験結果を解析するにあたり，まず，粘性，弾 性とも非線形である場合の応力緩和の一般諭を考察して おくことが必要となった。

Nakada ${ }^{2)}$ は Bolzmann の重ね合せ原理のなりたたない 非線形刺激一応答理論を展開し, 刺激 $x(t)$ に対する応答 $y(t)$ は

$$
y(t)=\int_{-\infty}^{+\infty} B_{1}(t-u) x(u) d u
$$

* 東京大学生産技術研究所(東京都港区麻布新竜土町 10)

$$
\begin{aligned}
& +\int_{-\infty}^{+\infty} \int_{-\infty}^{+\infty} B_{2}\left(t-u_{1}, t-u_{2}\right) x\left(u_{1}\right) x\left(u_{2}\right) d u_{1} d u_{2} \\
& +\int_{-\infty}^{+\infty} \int_{-\infty}^{+\infty} \int_{-\infty}^{+\infty} B_{3}\left(t-u_{1}, t-u_{2}, t-u_{3}\right) \\
& \quad \cdot x\left(u_{1}\right) x\left(u_{2}\right) x\left(u_{3}\right) d u_{1} d u_{2} d u_{3} \\
& \quad+\cdots \ldots
\end{aligned}
$$

で表わされるとした。右辺第 1 項は Bolzmann の重ね合 せ原理に相当し，非線形性を代表する第 1 項以下は，観 測時刻 $t$ 以前の多くの時刻における刺激の積が $t$ におけ る応答に及ぼす寄与の重ね合せに相当する。この式は, たとえば非線形応力緩和に対しても, その非線形性が現 象論的にどのような内容であるか, 重要な根本的知見を 与える最も一般的な基礎式（一次元非線形粘弾性論とし ての）であるが，実際の緩和関数がどのような形をとる かについては教えていない。

Schremp ら 3 は一般化 Maxwell-model の粘性を Eyring 粘性によって置き換えたモデルを用いて, 非ニュー トン流停止後の応力綑和を解析し, 緩慢な緩和機構に対 する緩和スペクトルを求める方法学提案したが，この場 合, 弾性要素は Hooke 法則にしたがうとする EyringTobolsky の粘弾性モデル4）が使われているので，本報 
で取り扱うような, recoverable strain が著しい非 Hooke 挙動を示す試料に対して, そのまま, 適用してよいかど うか疑問である。

Devries ら ${ }^{5)}$ は Eyring 理論を基礎として, 粘性, 弾 性両者梁非線形である場合の応力綏和を取り报ったが, 綏和応力 $\sigma$ を時間の関数として表現するには至らなかっ たように思われる。

いずれにしても, 粘性, 弾性両者とも非ニュートン, 非 フック的である場合の応力緩和を実用的な関数の形で表 現することはむずかしいことであろう。そこで，本報で は, 最初に述へた実験事実を説明するための基礎として, 応力緩和の長時間後の挙動に対して形式論的な一般解を 提出して，次報（II）の議論の前提としたいと思う。

次章に述べる形式論は, Maxwell の応力緩和式におけ る緩和時間 $\tau$ が，そのときの応力 $\sigma$ の単調減少関数であ るという，かなり広く認められている概念，または実験 的事実（すでに Maxwell によって示唆された）を基礎と する。

\section{2. 非線形応力緩和終端域の一般的挙動}

応力緩和に対する Maxwell の一般式は

$$
\frac{d \sigma}{d t}=-\frac{\sigma}{\tau}
$$

$\tau$ は $\sigma$ の単調减少関数とする。 $\tau$ を規定すると考えられ る $\sigma$ の関数としての非ニュートン粘性 ク, および非フ ック弾性 $G$ は $\sigma \rightarrow \sigma^{*}$ ( $\sigma$ が小さく, 線形粘弾性諭の成立 する範囲の $\sigma$ を $\sigma^{*}$ で表わすことにする) のとき， $\eta \rightarrow$

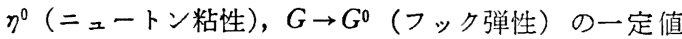
に，それぞれ収れんするというのが通念である。したが って, $\tau$ も $\sigma \rightarrow \sigma^{*}$ のとき, 一定值 $\tau^{0}=\eta^{0} / G^{0}$ に収れんす るものとする。たとえば, Eyring-Tobolsky のモデル4), Devries のモデル5) においても， $\sigma \rightarrow \sigma^{*}$ のとき, $\tau \rightarrow \tau^{0}$ で ある。すなわち，

$$
\tau^{0} \geqq \tau \geqq 0
$$

とする。

そこで，てをべき級数に展開し，

$$
\tau=\tau^{0}\left(1+a \sigma+b \sigma^{2}+c \sigma^{8}+\cdots \cdots\right)
$$

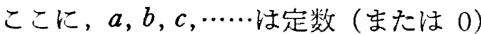

(2) 式より, $a \sigma+b \sigma^{2}+c \sigma^{3}+\cdots \cdots$ は

$$
0 \geqq a \sigma+b \sigma^{2}+c \sigma^{3}+\cdots \cdots \geqq-1
$$

なる $\sigma$ の単調減少関数とする。

（3）式を（1）式に入れて，変数分離すると，

$$
\left(\frac{1}{\sigma}+a+b \sigma+c \sigma^{2}+\cdots \cdots\right) d \sigma=-\frac{d t}{\tau^{0}}
$$

$t=0$ のとき $\sigma=\sigma_{0}$ として積分すると，

$$
\begin{aligned}
\ln \frac{\sigma}{\sigma_{0}} & +\left(a \sigma+\frac{b}{2} \sigma^{2}+\frac{c}{3} \sigma^{3}+\cdots \cdots\right) \\
& -\left(a \sigma_{0}+\frac{b}{2} \sigma_{0}{ }^{2}+\frac{c}{3} \sigma_{0}^{3}+\cdots \cdots\right)
\end{aligned}
$$

$$
=-\frac{t}{\tau^{0}}
$$

先に述べたように, $a \sigma+b \sigma^{2}+c \sigma^{3}+\cdots \cdots<0$ で $\sigma \rightarrow \sigma^{*}$ の とき, $a \sigma^{*}+b \sigma^{* 2}+c \sigma^{* 3}+\cdots \cdots \rightarrow 0$ と仮定したから, $(a \sigma+$ $\left.b \sigma^{2}+c \sigma^{3}+\cdots \cdots\right) / \sigma$ 嫦に傎である。

したがって, $\int_{0}^{x}\left(a \sigma+b \sigma^{2}+c \sigma^{3}+\cdots \cdots\right) / \sigma \cdot d \sigma$ は $x$ に関 し, 負の単調減少関数である。ただし, $0<x<+\infty$ とす る。ゆえに, $t \rightarrow$ 大の終端領域で, $\sigma^{*} \ll \sigma_{0}$ とすれば,

$$
\begin{aligned}
& \left|\int_{0}^{\sigma^{*}} \frac{\left(a \sigma+b \sigma^{2}+c \sigma^{3}+\cdots \cdots\right)}{\sigma \cdot d \sigma}\right| \\
& \quad \ll\left|\int_{0}^{\sigma_{0}} \frac{\left(a \sigma+b \sigma^{2}+c \sigma^{3}+\cdots \cdots\right)}{\sigma \cdot d \sigma}\right|
\end{aligned}
$$

すなわち，

$$
\begin{aligned}
& \left|a \sigma^{*}+\frac{b}{2} \sigma^{* 2}+\frac{c}{3} \sigma^{* 3}+\cdots \cdots\right| \\
& \ll\left|a \sigma_{0}+\frac{b}{2} \sigma_{0}^{2}+\frac{c}{3} \sigma_{0}^{3}+\cdots \cdots\right|
\end{aligned}
$$

よって, $t \rightarrow$ 大, $\sigma \rightarrow \sigma^{*}\left(\sigma^{*} \ll \sigma_{0}\right)$ の終端領域に関し, (6) 式は次のように近似することができる。

$$
\begin{array}{r}
\ln \frac{\sigma^{*}}{\sigma_{0}}-\left(a \sigma_{0}+\frac{b}{2} \sigma_{0}^{2}+\frac{c}{3} \sigma_{0}^{3}+\cdots \cdots\right) \fallingdotseq-\frac{t}{\tau^{0}} \\
\text { ここで, } \\
a \sigma_{0}+\frac{b}{2} \sigma_{0}{ }^{2}+\frac{c}{3} \sigma_{0}{ }^{3}+\cdots \cdots=A \quad A \leqq 0 \\
A=\ln B=2.303 \log B \quad 0<B \leqq 1
\end{array}
$$

とおけ过，(9) 式は

$$
\begin{gathered}
\sigma^{*} \fallingdotseq \sigma_{0} B e^{-t / \tau^{0}} \\
\frac{\sigma^{*}}{\sigma_{0}} \fallingdotseq B e^{-t / \tau^{0}}
\end{gathered}
$$

(12),（13）式は非線形応力緩和の終端域に対する形式 諭的な一般式であり， $B$ 証線形性を表わすパラメータ 一 $a, b, c, \cdots$, および, 緩和の初期応力 $\sigma_{0}$ を含む $t$ には 無関係な係数である。

$$
\sigma_{0} \rightarrow \text { 小のとき, } A \fallingdotseq 0, B \fallingdotseq 1 \text { であるから, }
$$

$$
\frac{\sigma^{*}}{\sigma_{0}} \fallingdotseq e^{-t / \tau 0}
$$

で Maxwell の緩和式となる（ $\sigma_{0}$ は小であるから， $\sigma^{*}=$ $\sigma$ とおきかえてよい)。すなわち, 非線形応力綏和の終端 領域法, Maxwell 物体の緩和関数 $e^{-t / \tau^{0}}$ に, 緩和の初期 条件によって決定する非線形係数 $B$ を乘したものとして 表現できるという重要な結果が得られた。

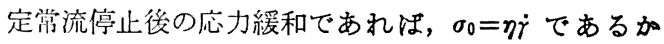

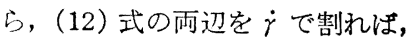

$$
\frac{\sigma^{*}}{\dot{\gamma}} \fallingdotseq \eta B e^{-t / \tau^{0}}
$$

一般に，非ニュートン粘性 $\eta$ は,

$$
\eta=\eta^{0}\left(1-\mu \dot{\gamma}^{2}+\nu \dot{\gamma}^{4}-\cdots \cdots \cdot\right)
$$

$\mu, \nu, \cdots \cdots:$ : 定数, $\eta^{0}:$ zero shear viscosity

したがって， 


$$
\begin{aligned}
& \frac{\boldsymbol{\sigma}^{*}}{\dot{\gamma}} \fallingdotseq \\
& \eta^{0}\left[\left(1-\mu \dot{\gamma}^{2}+\nu \dot{\gamma}^{4}-\cdots\right) B(a, b, c \cdots, \mu, \nu, \cdots, \dot{\gamma})\right] \cdot e^{-t / \tau^{0}}
\end{aligned}
$$

$(B(\quad)$ は $B$ が関数であることを示す $)$

いま, (17) 式で, $\dot{\gamma} \rightarrow 0$ とすれぼ, 当然, 定常流停止後 の Maxwell 緩和となる。

$$
\frac{\sigma^{*}}{\dot{\gamma}} \fallingdotseq \eta^{0} e^{-t / \tau^{0}}
$$

$$
\left(\sigma^{*}=\sigma\right. \text { としてよい) }
$$

よって，(17）式の $e^{-t / 70}$ の係数は，“応力綏和における 非ニュートン係数”とでる呼ぶべき係数である。簡単に するために，(17）式は

$$
\frac{\sigma^{*}}{\dot{\gamma}} \fallingdotseq \eta^{*} e^{-t / \tau^{0}}
$$

\section{と書くことにする。}

以上, 総括するに, 非ニュートン流停止後の応力綏和 を $\log \sigma / \sigma_{0} \sim t$ または, $\log \sigma / \dot{\gamma} \sim t$ の形でブロットした 緩和曲線は, $t \rightarrow$ 大, $\sigma \rightarrow \sigma^{*}$ (小) の終端領域で, 定常流 の際の $\sigma_{0}$ (または, $\dot{r}$ ) の異なる場合, 平行な直線群と なる。直線の勾配より, 系の緩和時間 $\tau^{0}$ を, 切片 $(t \rightarrow 0$ に対する外挿値) より,「非線形係数」 $B$, または,「非二= 一トン倸数」 $\eta^{*}$ が求められることを意味する。

$B$ が求まれば，(10）式より

$$
\begin{aligned}
& \frac{d A}{d \sigma_{0}}=\frac{a \sigma_{0}+b \sigma_{0}{ }^{2}+c \sigma_{0}{ }^{3}+\cdots \cdots}{\sigma_{0}} \\
\therefore \quad & \frac{d \ln B}{d \ln \sigma_{0}}=a \sigma_{0}+b \sigma_{0}^{2}+c \sigma_{0}^{3}+\cdots \cdots .
\end{aligned}
$$

であるから，ての非線形項の形を, $\log B \sim \log \sigma_{0}$ の勾配 から決定できる。

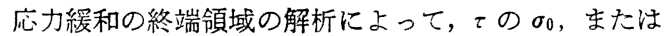
：依存性が，どのような形であるか知ることができると いうことは非常におもしろい結果といえよう。

次に，上述の形式論をチェックする意味で，G=const て, $\eta=\sigma / X \sinh (Y \sigma)$ なる Eyring 粘性尚に從うとする。 Tobolsky-Eyring のモデルの $\sigma \rightarrow \sigma^{*}$ における挙動を考察 しておこう。

(1) 式に相当する式は

$$
\frac{d \sigma}{d t}=-G X \sinh (Y \sigma)
$$

ただし，Eyring 理論によれば，

$$
\tau^{0}=\frac{1}{X Y G}
$$

$X, Y:$ 定数

（22）式の積分は,

$$
\tanh \left(\frac{Y \sigma}{2}\right)=\tanh \left(\frac{Y \sigma_{0}}{2}\right) \cdot e^{-t / \tau^{0}}
$$

$\sigma=\sigma^{*}$ のときは, $\tanh \left(\frac{Y \sigma_{0}}{2}\right) \fallingdotseq \frac{Y \sigma^{*}}{2}$ と近似できるから

$$
\sigma^{*} \fallingdotseq \frac{2}{Y} \tanh \left(\frac{Y \sigma_{0}}{2}\right) \cdot e^{-t / \tau 0}
$$

$$
\sigma^{*} \fallingdotseq \sigma_{0}\left\{1-\frac{2}{3 !}\left(\frac{Y}{2}\right)^{2} \sigma_{0}{ }^{2}+\frac{16}{5 !}\left(\frac{Y}{2}\right)^{4} \sigma_{0}^{4}-\cdots\right\} \cdot e^{-t / \tau^{0}}
$$

$$
\frac{\sigma^{*}}{\dot{\gamma}} \fallingdotseq \eta^{0}\left[\left(1-\mu \dot{\gamma}^{2}+\nu \dot{\gamma}^{4}-\cdots\right) \cdot f(\mu, \nu, \cdots, \dot{\gamma})\right] \cdot e^{-t / \tau 0}
$$

（26），(27）式は，(12)，(17）式とそれぞれ同形である。 本報では, 主として，(13)式を中心として，B, $A$ およ び $\tau$ の非線形項 $\left(a \sigma+b \sigma^{2}+c \sigma^{3}+\cdots \cdots \cdot\right)$ の実験結果による 検討を行なう。

\section{3. 実験方法}

既報1)と同じ二重円筒式回転粘度計。外筒はクラッチ 機構により, 回転, および, 急停止, 固定できる。内筒 にかかるトルクはストレンゲージによって検出記録す る。トルク検出時の内筒の角変位は試料の Recoverable strain に比べて十分小さく，応力緩和は一定变形下に進 行すると考えてよい。記録計の応答は応力緩和に十分泊 随できる。

試料はポリアクリル酸ナトリウム(Na-PAA),メチル セルロース $(\mathrm{MC})$ の溶液である。 Na-PAA は $\bar{M}_{v} \simeq$ 4200000 。測定漂度 $0.25 \sim 1.5 \mathrm{~g} / 100 \mathrm{ml}$ 。この場合, 鎖長 $z$ と容積分率 $v$ の積 $z v \simeq 230 \sim 1400$ で，通常の高分子の からまり合いの臨界值 $z_{c} v_{c} \simeq 240 \sim 1000$ に近く, PAA に 対する文献値 $z_{c} v_{c}=130^{7)}$ 上り大きい。 $\mathrm{MC}$ は非電解質 で, その粘弾性挙動は CMC や Na-PAA とかなり相違 する8)た放，現象の一般性を調べるために使用した。 MC は低濃度では応力緩和は急速で測定できない。また，高 濃度では均一な溶液の調製がむずかしい。測定濃度は 3 $\sim 4 \mathrm{~g} / 100 \mathrm{ml}$ の狭い範囲にとどまった。なお， CMCに 対する既報のデータ1)，およびポリイソブチレン(PIB) に対するSchrempらのデータ3゙についても検討を行なう ことにした。

実験結果を記述するにあたり， $\sigma$ としては内筒面の值， $\dot{\gamma}$ としてはニュートン流動を仮定して計算される内筒面

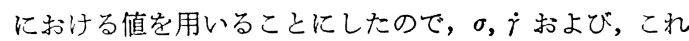
より誘導される量には，すべて添字 $i$ を付け加えること にした。

\section{4. 結果と考察}

$\log \left(\sigma_{i} / \sigma_{i 0}\right) \sim t$ でプロットした綑和曲線を Fig. 1 9 9 示す。Fig. 1 5 は種々な濃度の Na-PAA。Fig. 6 は Na$\mathrm{PAA} の 2 \mathrm{~N}, \mathrm{NaOH}$ 溶液。この場合は高分子電解質と しての性質は失われ，一般高分子の溶液状態に近いであ ろう。Fig. 7 は MC の一例。Fig. 8 は CMC (既報のデ

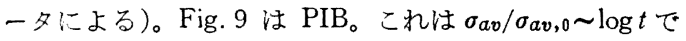
プロットした Schremp ら ${ }^{3)}$ の結果を $\log \left(\sigma_{a v} / \sigma_{a v, 0}\right) \sim t$ の形に換算したものである。添字 $a v$ は, 内外筒間の平 


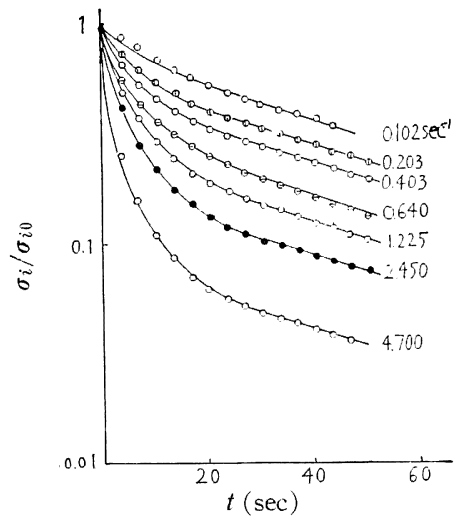

$\sigma_{i}:$ shear stress at the inner cylinder surface at time $t$

$\sigma_{i 0}: \quad \sigma_{i}$ at time $t=0$

$\mathrm{Na}-\mathrm{PAA}: \mathrm{Na}$-polyacrylate

$\mathrm{Na}-\mathrm{PAA}, 0.25 \mathrm{~g} / 100 \mathrm{ml}, 25^{\circ} \mathrm{C}$

Fig. 1. Stress relaxation following non-Newtonian flow.

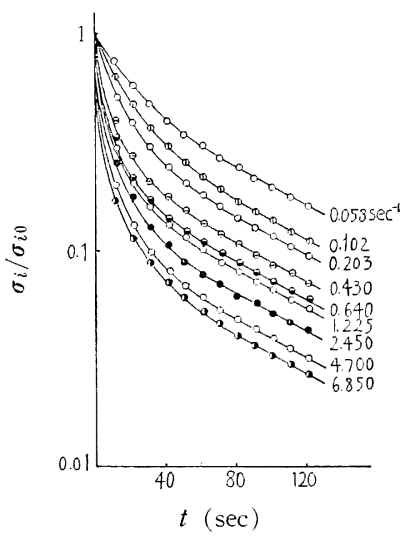

$\mathrm{Na}-\mathrm{PAA}, 0.5 \mathrm{~g} / 100 \mathrm{ml}, 25^{\circ} \mathrm{C}$

Fig. 2. Stress relaxation following non-Newtonian flow.

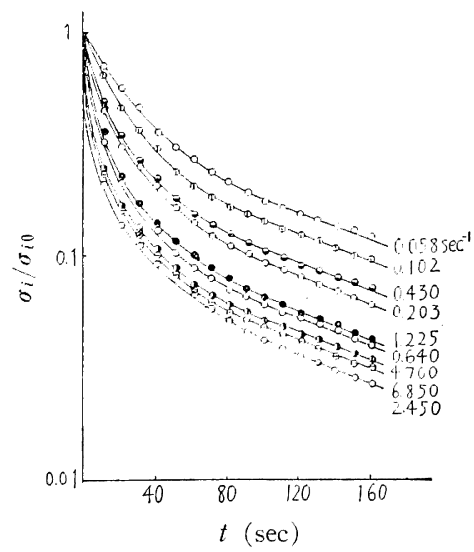

$\mathrm{Na}-\mathrm{PAA}, \quad 0.75 \mathrm{~g} / 100 \mathrm{ml}, 25^{\circ} \mathrm{C}$

Fig. 3. Stress relaxation following non-Newtonian flow.

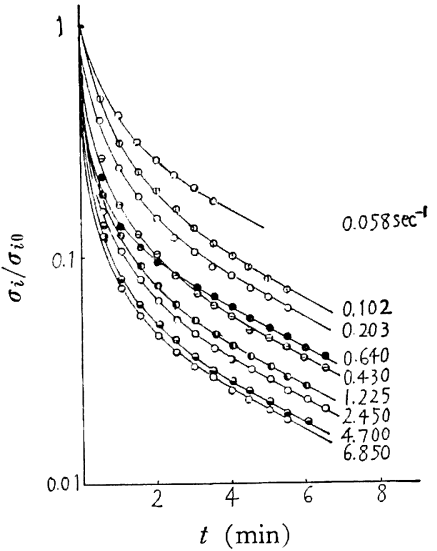

$\mathrm{Na}-\mathrm{PAA}, 1 \mathrm{~g} / 100 \mathrm{ml}, 25^{\circ} \mathrm{C}$

Fig. 4. Stress relaxation following non-Newtonian flow.

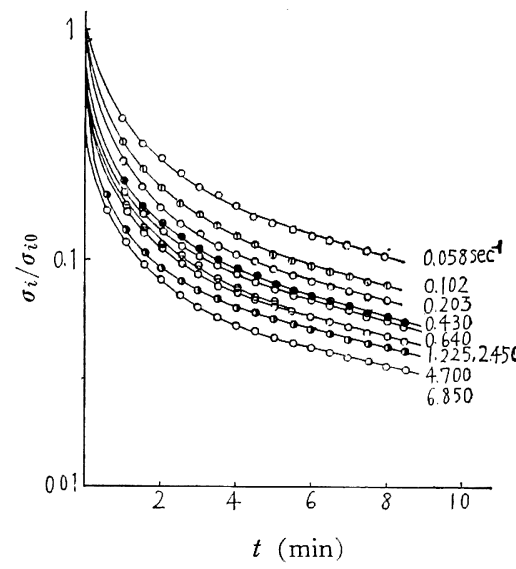

Na-PAA, $1.5 \mathrm{~g} / 100 \mathrm{ml}, 25^{\circ} \mathrm{C}$

Fig. 5. Stress relaxation following non-Newtonian flow.

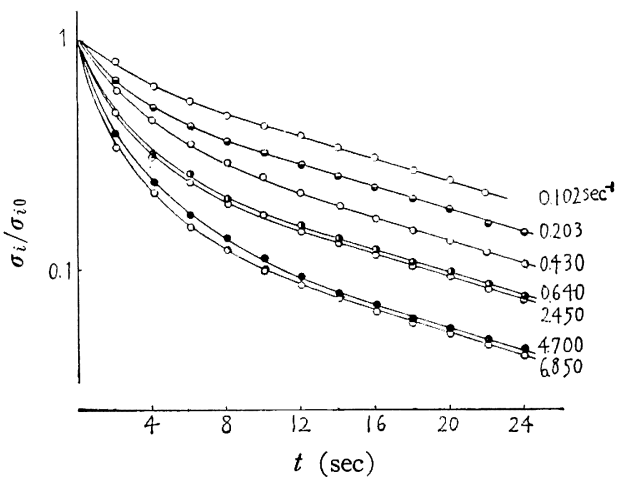

$\mathrm{Na}-\mathrm{PAA}, 1.5 \mathrm{~g} / 100 \mathrm{ml}, 2 \mathrm{~N}-\mathrm{NaOH}, 25^{\circ} \mathrm{C}$

Fig. 6. Stress relaxation following non-Newtonian flow. 


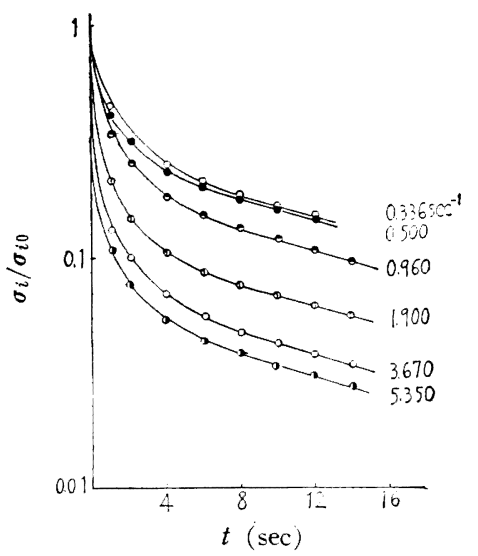

MC, $3.5 \mathrm{~g} / 100 \mathrm{ml}, 25^{\circ} \mathrm{C}$

MC: Methylcellulose

Fig. 7. Stress relaxation following non-Newtonian flow.

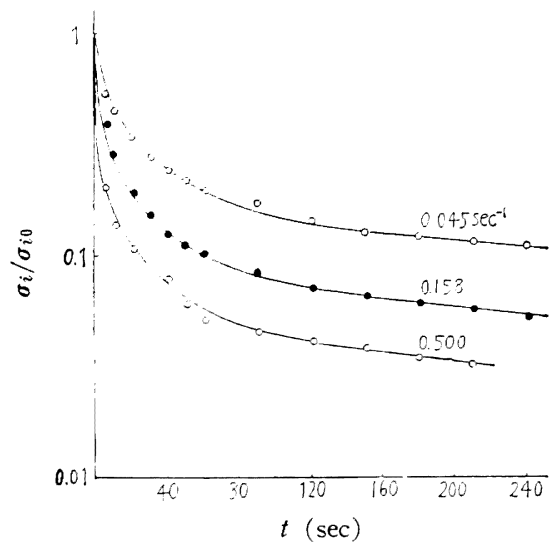

$\mathrm{Na}-\mathrm{CMC}, 3 \mathrm{~g} / 100 \mathrm{ml}, 25^{\circ} \mathrm{C}$

Na-CMC: Na-Carboxymethylcallulose

Fig. 8. Stress relaxation following non-Newtonian flow.

\section{均値を示す。}

すべての図で明らかに $t \rightarrow$ 大の終端域は平行な直線と なっていると見てよいであろう。少なくとも形式上, (13) 式はなりたっている。 $\log \left(\sigma_{i} / \dot{\gamma}_{i}\right) \sim t$ 曲線は $\log \left(\sigma_{i} / \sigma_{i 0}\right)$ $\sim t$ 曲線を垂直に $\log$ 座標上, $\eta_{i}$ だけ平行移動した場合 にすぎないら,緒言で述べた応力紘和終端域の挙動は, 試料に関係なく，一般的な現象であると考えてよかろう （また，このこと法，特殊なモデルを用いない一般的な 形式論の結果である(15)式の要請でもある)。

Fig. 1 9 で直線部の勾配 $\tau^{0}$ が非ニュートン流の影響 を受けない試料の定数であることは上述のとおり，すで に明らかである。

次に，直線部を $t \rightarrow 0$ に外挿して得る $\log \left(\sigma_{i} / \sigma_{i 0}\right)$ 軸の
切片 $B$ が理論の要求に合うかどうか調べる。

Fig. 10 は Fig. 1〜5より得た $B$ を， $\log B \sim \sigma_{i 0}$ でプ ロットした結果である。この図は（11）式より明らかな ように，B=1のところに $A=0, B=0.1$ のところに $A$ $=-2.303$ と書いて等分目盛にすれば, $A \sim \sigma_{i 0}$ の関係と 同等である。 $\sigma_{i 0}$ の小さい部分の曲線の曲り方は,あまり 明かではないが，少なくとも無理なく， $\sigma_{i 0} \rightarrow 0$ のとき $B$ $\rightarrow 1$ は可能のようで, $B$ が 1 より小さい減少関数である という(9)〜 (13)式の要求を満たしていると考えられる。 Fig. 11 でも, 試料の差異にかかわりなく, (9)〜 (13) 式 は满足されていると見られる。

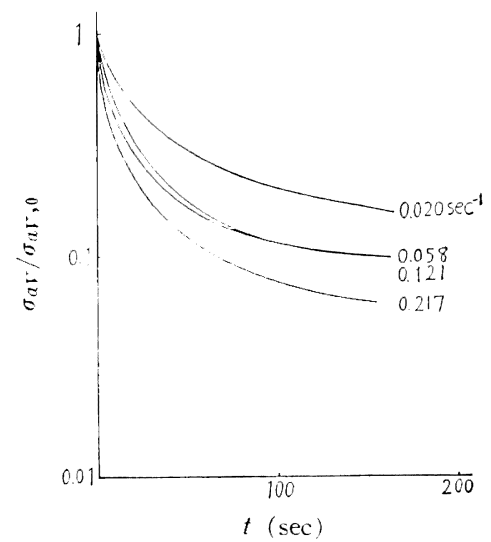

PIB, $16.5 \%$ in decaline, $15^{\circ} \mathrm{C}$

PIB: Polyisobuthylene

$\sigma_{a v} / \sigma_{a V, 0} \sim \log t$ curves given by Shremp et al. ${ }^{3)}$ was reduced to $\log \left(\sigma_{a V} / \sigma_{a V, 0}\right) \sim t$ curves.

Suffix av means an average value.

Fig. 9. Stress relaxation following non-Newtonian flow.

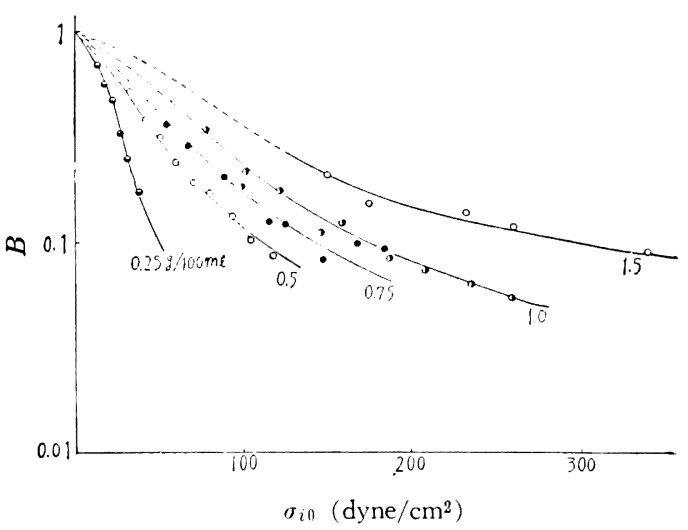

Na-PAA, $25^{\circ} \mathrm{C}$

Fig. 10. Coefficient $B$ in eq. (13) determined from straight portion of relaxation curves in Fig. $1 \sim \bar{j}$. 
次に，(21）式により， $\left(a \sigma_{i 0}+b \sigma_{i 0}{ }^{2}+c \sigma_{i 0}{ }^{3}+\cdots \cdots\right)$ の形 を求めるため, $\log B \sim \log \sigma_{i 0}$ でプロットしたのが, Fig. 12，Fig. 13 である。これらの曲線の勾配は 0 と一1 の間 にあることが，(4) 式の要請であるが, Fig. 12 の $0.25 \mathrm{~g}$ $/ 100 \mathrm{ml}, 0.5 \mathrm{~g} / \mathrm{ml}$ の場合, この要請に合わない部分のあ るととがわかる。また，Fig. $12 て ゙, ~ 0.75 \mathrm{~g} / 100 \mathrm{ml}$ の $\sigma_{i 0}$ 〜100 付近で曲線が二つの方向に向う可能性のあること が認められる。さらに, Fig. 12 で, 1 g/100 ml の曲線が, やはり $\sigma_{i 0} \simeq 100$ 付近で不連続的になっていると考えられ る部分が見られる。これらの現象をあわせ考えると, $\mathrm{Na}$ -PAA 溶液はズリに対して不安定なところがあり, $(d \log$ $\left.B / d \log \sigma_{i 0}\right)<-1$ のような (4) 式に相反する現象が起こ るのは，単一連続な物体に対して考元られている (1) 式 か，物体の力学的性質に不連続的变化を起こす $\mathrm{Na}-\mathrm{PAA}$ 溶液に対して常になりたつものでないことを示すものと 考えられる。換言すれば, 0.25 0.5g/100 ml の Na-PAA などに対しては， $\sigma_{i 0}$ の大きさに応じて，(4) 式のパラメ 一ター $a, b, c, \cdots \cdots$ などの変化することが考えられる。 これらの問題については次報で再び述べる。

（4）式の要求に合わない例をまず述べたが, 他の試料 の例を見ると， $\sigma_{i 0} \rightarrow$ 大のとき $\left(d \log B / d \log \sigma_{i 0}\right)$ はほと んど -1に一定してしまうのが認められる(勾配 -1 の 直線で近似できる)。ゆえに，特殊な場合を除き，多くの 場合，（4）式もまた成立するものと考光てよいである う。

上述のように， $\sigma=\sigma_{0}$ のとき，本報で取り扱ったほと

$\ominus:$ MC, $3.5 \mathrm{~g} / 100 \mathrm{ml}, \quad$ O: $\mathrm{CMC}, 3.0 \mathrm{~g} / 100 \mathrm{ml}$

O: PIB, $16.5 \%$

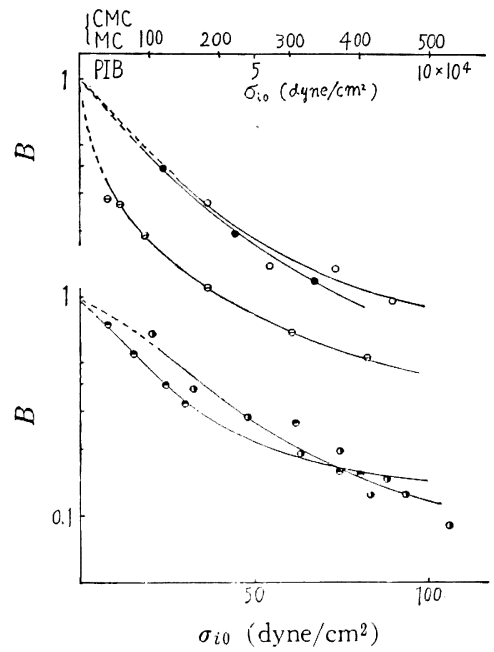

$\mathrm{Na}-\mathrm{PAA}$ in $2 \mathrm{~N}-\mathrm{NaOH}$

๑: $1.5 \mathrm{~g} / 100 \mathrm{ml}, \quad$ : $2.0 \mathrm{~g} / 100 \mathrm{ml}$

Fig. 11. Coefficient $B$ determined from straight portions of curves in Fig. $6 \sim 9$.
んどすべての試料において $\left(a \sigma_{0}+b \sigma_{0}{ }^{2}+c \sigma_{0}{ }^{3}+\cdots\right) \simeq-1$,

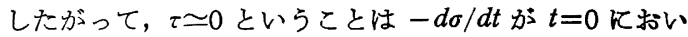
て，低近い大きさを持っていることを表わしている。 このことは Tobolsky-Eyring のモデル, Devries らのモデ ルでも同様であり，理論的な欠陷ではなかろう。すなわ ち, Tobolsky-Eyring モデルで, $\sigma=\sigma_{0} \gg 1 / Y$ とすれば, (23) 式は

$$
-\frac{d \sigma_{0}}{d t} \fallingdotseq \frac{G X}{2} \cdot e^{Y \sigma_{0}}
$$

Devries モデルでは,

$$
-\frac{d \sigma}{d t}=\frac{\sigma}{\tau^{0}} \cdot \cosh \left(\sigma / G^{0}\right)
$$

で, $\sigma=\sigma_{0} \gg G^{0}$ の条件では

$$
-\frac{d \sigma_{0}}{d t} \fallingdotseq \frac{\sigma_{0}}{\tau^{0}} \cdot \frac{e^{\sigma_{0} / G^{0}}}{2}
$$

で, 一 $d \sigma_{0} / d t$ は非常に大きな值をとるものと推定される。

Fig. 12,13 で点線で表わした外挿曲線部分を一応正し いものと仮定し， $\sigma_{0}$ の各值で勾配を計算し，これを $\left(a \sigma_{0}\right.$ $\left.+b \sigma_{0}{ }^{2}+c \sigma_{0}{ }^{3}+\cdots \cdots\right)$ に等しいものとして $\sigma_{0}$ に対してブ

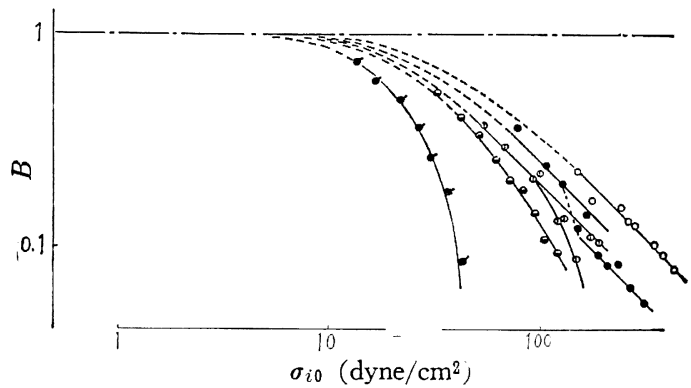

Na-PAA, $25^{\circ} \mathrm{C}, \mathbf{O}^{\prime}: 0.25 \mathrm{~g} / 100 \mathrm{ml}$, ○: $0.50 \mathrm{~g} / 100 \mathrm{ml}$, (1): $0.75 \mathrm{~g} / 100 \mathrm{ml}$, : $1.00 \mathrm{~g} / 100 \mathrm{ml}, \bigcirc: 1.50 \mathrm{~g} / 100 \mathrm{~m} l$ $d \log B / d \log \sigma_{i 0}=a \sigma_{i 0}+b \sigma^{2} i 0+c \sigma^{3} i 0$

Fig. 12. $\log \sim \log$ plots of $B \sim \sigma_{i 0}$

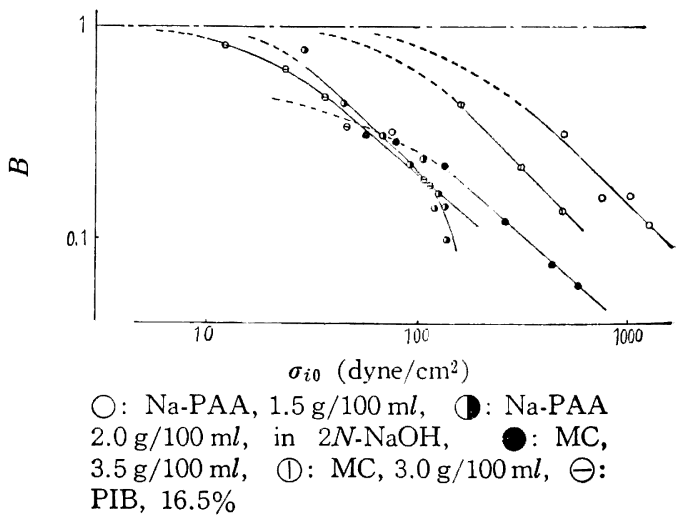

Fig. 13. $\log \sim \log$ plots of $B \sim \sigma_{i 0}$ 
ロットした例が Fig. 14 である。

Fig. 15,16 亿 Na-PAA の非二ニートン粘性 $\eta_{i}$ の $\dot{\gamma}_{i}$ 依 存性と, 応力緩和の非線形係数 $B$ の $\dot{\gamma}_{i}$ 依存性を比較し てみた。 $B$ の方が $\dot{\gamma}$ 依存性が小さく $B$ の絶対值は $\eta_{i}$ のそれに比べて，濃度が小さいほど大きいということが わかる。

Fig. 17，18 は，MC，PIB に関する同様な比較である が，MC の場合には $B$ の $\dot{\gamma}_{i}$ 依存性の方が $\eta_{i}$ のそれよ り大きい。すなわち，一般的傾向と呼ぶべきものは存在 しない。

\section{5. 結 論}

一般に, 粘弾性液体の非線形応力緩和の終端領域は, Maxwell の応力䌅和の緩和関数 $e^{-t / \mathrm{r}^{0}}$ の係数として, $t=$ 0 の初期条件によって決まる, ある応力（または, ズリ 速度）の関数を乗じた形で表現できることを形式理諭の 結果として導き，かなり性質の異なる試料に対して実験

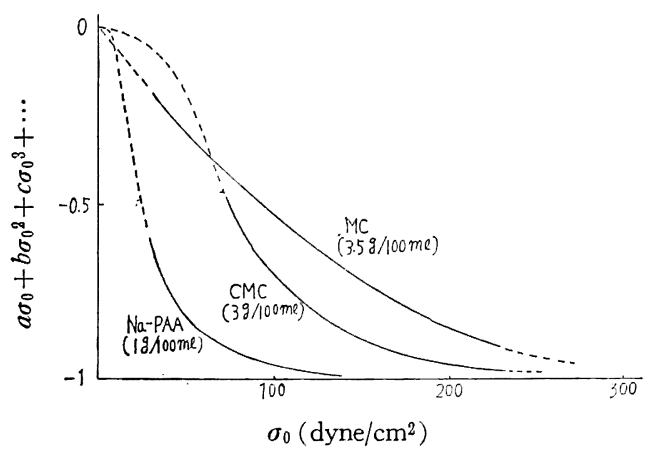

These curves may represent the dependence of $\tau$ in eq. (1) on $\sigma$.

Fig. 14. Assumed curves of $\left(a \sigma_{0}+b \sigma_{0}{ }^{2}+c \sigma_{0}{ }^{3}+\cdots\right)$, estimated from Fig. 12, and Fig. 13.

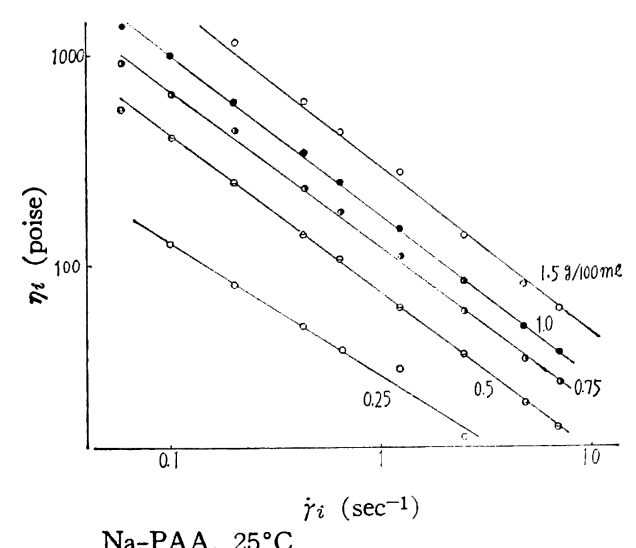

Fig. 15. The dependence of non-Newtonian viscosity $\eta_{i}$ on $\dot{\gamma}_{i}$.

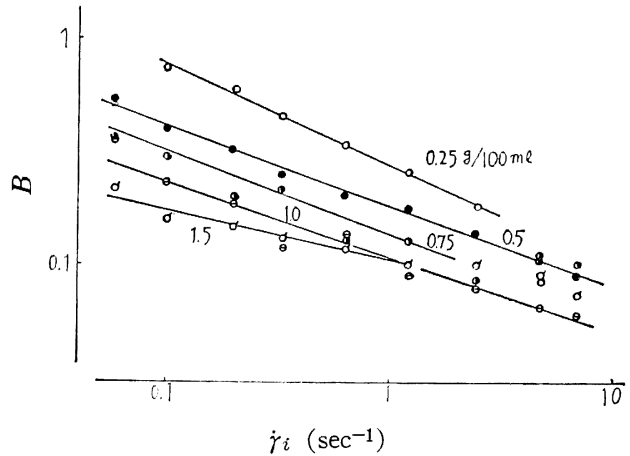

NA.PAA, $25^{\circ} \mathrm{C}$

(compare with Fig. 15)

Fig. 16. The dependence of $B$ on $\dot{\gamma}_{i}$.

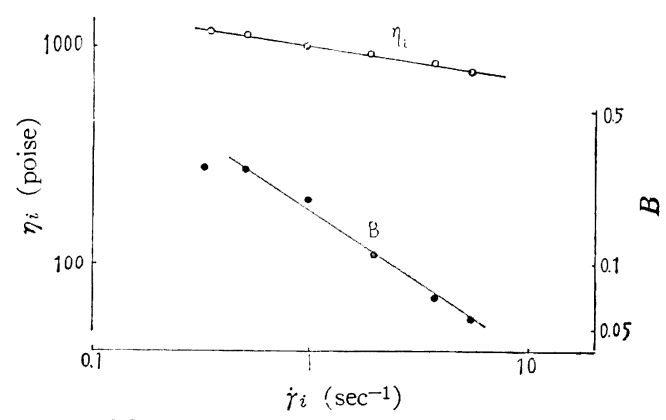

MC, $3.5 \mathrm{~g} / 100 \mathrm{ml}, 25^{\circ} \mathrm{C}$

Fig. 17. Comparison of the dependencies of $\eta_{i}$ and $B$ on $\dot{\gamma}_{i}$.

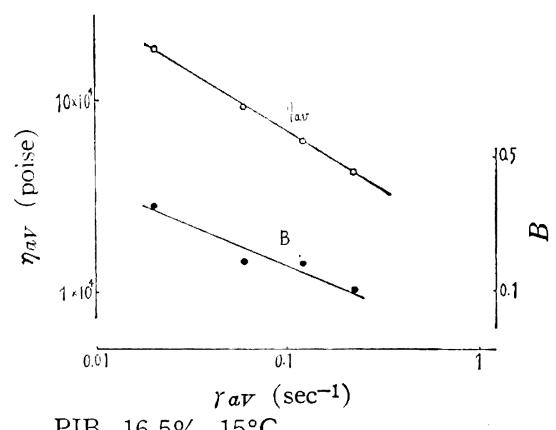

Fig. 18. Comparison of the dependencies of $\eta_{a r}$ and $B$ on $\dot{\gamma} a v$.

的にも妥当であることを示した。

試料の粘弾性に対し, その機構の多様性を全く考虑し ない上述の形式論では, 実験結果から物理的内容を引き 出すことはできないが，次報以下で述べるように，上述 の非線形挙動の数式的表現方法は, 多くの応用が見出さ れるであらう。

なお，物体が外力によって連続的関数の形で応答する 
とする形式論で流，必ずしも説明できないと推定される ような現象もあるよう汇思わ机る。

付 記：本報の一部は第14回レオロジー討論会で発 表したデータを含む。

\section{文献}

1）黑岩城雄, 全昌 中, 中村亦夫：高化, 23, 11 (1966)

2) O. Nakada: J. Phys. Soc. Japan, 15, 2280 (1960)

3) F. W. Schremp, J. D. Ferry, W. W. Evans :
J. Appl. Phys, 22, 711 (1951)

4) A. Tobolsky, H. Eyring: J. Chem. Phys., 11, 125 (1943)

5) A. J. Devries, J. Tochon: J. Appl. Polymer Sci., 7, 315 (1963)

6) S. Glasstone, J. Laidler, H. Eyring: "The Theory of Rate Process" 480 (1941) McGraw-Hill Co.

7) J. G. Brodnyan, E. L. Kelley: Trans. Soc. Rheol., 7, 125 (1963)

8）黑岩城雄，中村亦夫：高化，22，9（1965）

\title{
Stress Relaxation Following Non-Newtonian Flow
}

\section{A Formal Theory for the Terminal Region of Non-Linear Stress Relaxation}

\author{
By Shiro Kuroiwa* and Matao Nakamura*
}

The general Maxwell formula for stress relaxation is:

$$
\frac{d \sigma}{d t}=-\frac{\sigma}{\tau}
$$

It is assumed that $\tau$, a monotonously decreasing function of stress $\sigma$, is desribed by

$$
\tau=\tau^{0}\left(1+a \sigma+b \sigma^{2}+c \sigma^{3}+\cdots \cdots\right)
$$

where $a, b, c, \cdots \cdots$ are material constants, $0 \geqq a \sigma+b \sigma^{2}+c \sigma^{3}+\cdots \cdots \geqq-1$ and $\tau^{0}$ is a relaxation time of the system at small stresses. From eq. (1) and (2) the following equation for the terminal region of relaxation is derived.

$$
\frac{\sigma^{*}}{\sigma_{0}} \fallingdotseq B e^{-t / \tau^{0}}
$$

where $\sigma_{0}$ is the $\sigma$ at $t=0, \sigma^{*}$ means small stresses under which the general linear viscoelastic theory is applicable and $B$ is a function of $\sigma_{0}$ and is independent of $t$.

If $\sigma_{0}=\eta \dot{\gamma}$ ( $\dot{\gamma}$ : shearing rate, $\eta$ : non-Newtonian viscosity), eq. (3) becomes:

$$
\frac{\sigma^{*}}{\dot{\gamma}} \fallingdotseq \eta B e^{-t / \tau 0}=\eta^{*} e^{-t /=0}
$$

$r^{*}$ may be called "a non-Newtonian coefficient in stress relaxation following flow".

The functional form of the non-linear terms of $\tau$, i.e., $\left(a \sigma+b \sigma^{2}+c \sigma^{3}+\cdots \cdots\right)$ may be estimated as

$$
\frac{d \log B}{d \log \sigma_{0}}=a \sigma_{0}+b \sigma_{0}{ }^{2}+c \sigma_{0}{ }^{3}+\cdots \cdots
$$

The above macroscopic formal theory is compared with the theory described by Eyring-Tobolsky and checkd by various non-linear viscoelastic solutions.

Applications of the proposed theory will appear in the next report (II).

\footnotetext{
* Institute of Industrial Science, The University of Tokyo (Azabu-Shinryudo-cho, Minato-ku, Tokyo).
} 